\title{
100-Gb/s Electro-Absorptive Duobinary Modulation of an InP-on-Si DFB Laser
}

\author{
A. Abbasi ${ }^{\circledR}$, J. Verbist ${ }^{\circledR}$, L. A. Shiramin ${ }^{\circledR}$, M. Verplaetse ${ }^{\circledR}$, T. De Keulenaer, R. Vaernewyck, \\ R. Pierco, A. Vyncke, X. Yin ${ }^{\circledR}$, G. Torfs ${ }^{\circledR}$, G. Morthier ${ }^{\circledR}$, J. Bauwelinck ${ }^{\circledR}$, and G. Roelkens ${ }^{\circledR}$
}

\begin{abstract}
Gb/s single-channel optical data communication transceivers can provide a compact and cost-effective solution for the exponentially growing data-center traffic. One of the enabling technologies is electro-absorption-modulated single-mode lasers which are very compact, efficient, and fast. In this letter, such a transmitter integrated on a silicon photonics platform is demonstrated. While low loss and high contrast waveguides are provided by $\mathrm{Si}$ photonics, the gain and efficient electroabsorption are provided by the InP-based multi-quantum-well structure. A lumped electro-absorption modulator integrated with a distributed feedback laser is designed and fabricated in this platform. The epitaxial stack is identical for the laser and the modulator, which eases the fabrication process considerably. In this way, we successfully demonstrate $100-\mathrm{Gb} / \mathrm{s}$ single-channel electrical duobinary optical data transport over $\sim 100 \mathrm{~m}$ of fiber with a bit error rate of 1.6e-3.
\end{abstract}

Index Terms-Electro-absorption, DFB lasers, heterogeneous integration, silicon photonics.

\section{INTRODUCTION}

D ATA traff $\mathrm{c}$ is increasing exponentially owing to the rapid growth of cloud services and wireless applications. As a result, the required Ethernet transceiver capacity is increasing rapidly. 100-gigabit Ethernet (100GbE) was standardized by IEEE in 2010 [1] specifying four $25 \mathrm{~Gb} / \mathrm{s}$ non-return-to-zero on-off keying (NRZ-OOK) channels. The four lanes are allocated on a local area network

Manuscript received March 11, 2018; revised April 16, 2018; accepted May 1, 2018. Date of publication May 4, 2018; date of current version May 22, 2018. This work was supported in part by the Belgian IAP network Photonics@be 14/GOA/034, in part by the UGent special research fund BOF, and in part by the Hercules Program through the Flemish Government. (Corresponding author: A. Abbasi.)

A. Abbasi, L. A. Shiramin, G. Morthier, and G. Roelkens are with the Photonics Research Group, Department of Information Technology, imec, 9000 Ghent, Belgium, and also with the Center for Nano and Biophotonics, Ghent University, 9000 Ghent, Belgium (e-mail: amin.abassi@ugent.be; leili.abdollahishiramin@ugent.be; geert.morthier@ ugent.be; gunther.roelkens@ugent.be).

J. Verbist is with the Photonics Research Group, Department of Information Technology, imec, 9000 Ghent, Belgium, also with the Center for Nano and Biophotonics, Ghent University, 9000 Ghent, Belgium, and also with the IDLab, Ghent University, imec, 9052 Gent, Belgium (e-mail: jochem.verbist@ugent.be).

M. Verplaetse, X. Yin, G. Torfs, and J. Bauwelinck are with the IDLab, Ghent University, imec, 9052 Gent, Belgium (e-mail: michiel.verplaetse@ugent.be; guy.torfs@ugent.be; xin.yin@ugent.be; johan.bauwelinck@ugent.be).

T. De Keulenaer, R. Vaernewyck, R. Pierco, and A. Vyncke are with BiFAST, imec, 9000 Ghent, Belgium (e-mail: timothy@bifast.io; renato@bifast.io; ramses@bifast.io; arno@bifast.io). wavelength division multiplexing (LAN-WDM) grid with $800-\mathrm{GHz}$ spacing at $1.3 \mu \mathrm{m}$. For $400 \mathrm{GbE}$, similar standards are emerging using 50 Gbaud PAM-4. However, the use of these advanced modulation formats puts stringent requirements on the electronics (linearity) and optical channel (signal to noise ratio). This will impact the cost of such transceivers, which is of paramount importance for intra-datacenter links. Therefore there is an interest in transceivers that allow for $100 \mathrm{Gbit} / \mathrm{s}$ operation per wavelength using simpler modulation formats.

Previously, several $100 \mathrm{~Gb} / \mathrm{s}$ single-lane transmission demonstrations have been realized using four level pulse amplitude modulation (PAM-4) [2]-[5] and discrete multitone (DMT) [6]. However, many of these experiments still rely on complex digital signal processing (DSP) at the RX and/or TX-side, typically done off ine. On the other hand, $100 \mathrm{~Gb} / \mathrm{s}$ NRZ-OOK modulation requires a very high modulation bandwidth (>50 GHz). The 100-Gb/s NRZ-OOK operation of a traveling-wave type electro-absorption modulator integrated with a distributed feedback laser (TW-EADFB laser) has been reported [7], [8]. The transmission line design of the TW-EADFB laser slightly increases the overall device size when compared to a lumped modulator and it also needs a power-consuming $50 \Omega$ termination. The impact of this power and size increase should however be viewed in the context of the entire packaged module, as other factors (f ber coupling loss, EAM insertion loss, DFB eff ciency, temperature control) can overshadow these savings. The combination of state-ofthe-art SiGe electro-absorption (EA) modulators on a silicon photonics platform with state-of-the-art modulator drivers has resulted in a fi st real-time serial $100 \mathrm{~Gb} / \mathrm{s}$ NRZ-OOK transmission [9], [10]. However, in this demonstration the laser source was not integrated on the photonic integrated circuit.

Electrical duo-binary (EDB) modulation is an intensity modulation format that relaxes the bandwidth requirements on the optical components and still offers a simple demodulation scheme. EDB was used to demonstrate real time $100 \mathrm{~Gb} / \mathrm{s}$ transmission based on an InP travelling-wave electroabsorption modulator with integrated DFB laser [9]. However, as mentioned earlier, the $50 \Omega$ termination for such a transmission line structure increases the power consumption. Using a silicon-organic Mach-Zehnder modulator $100 \mathrm{~Gb} / \mathrm{s}$ electrical duobinary transmission was demonstrated [11] at the cost of large footprint and $50 \Omega$ termination. Also, in this case the laser source was not integrated. In this letter, we present 

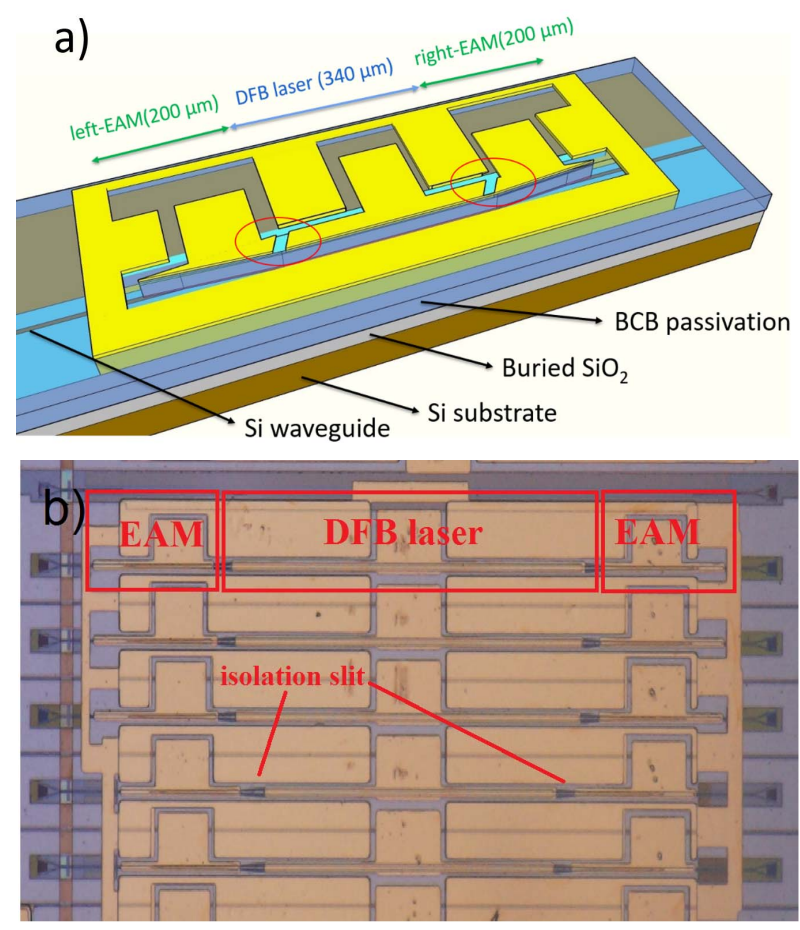

Fig. 1. (a) Schematic of the heterogeneously integrated InP-on-Si externally modulated laser (tilted isolation slits' position is indicated by red circles); b) Microscope image of the fabricated device showing the central DFB laser and the EAMs implemented in the tapers.

the frst demonstration of the transmission of a $100 \mathrm{~Gb} / \mathrm{s}$ electrical duobinary signal using a heterogeneously integrated InP-on-Si externally modulated DFB laser (EML) combined with an in-house designed transmitter (TX-IC) chipset in SiGe BiCMOS technology, without the need for any digital signal processing (DSP). A bit error rate (BER) of $1.6 \mathrm{e}-3$ is obtained for transmission over $\sim 100 \mathrm{~m}$ of single mode $\mathrm{fber}$, which is below the hard decision forward error coding limit with $7 \%$ overhead of $3.8 \mathrm{e}-3$.

\section{Heterogeneously Integrated Transmitter}

The transmitter is a heterogeneously integrated III-V-on-Si electro-absorption DFB laser. The EML was realized through adhesive die-to-wafer bonding on a silicon photonic integrated circuit, schematically illustrated in Fig. 1(a). The EAM is implemented in the III-V taper, which is used to couple the light between the $\mathrm{InP}$ and the $\mathrm{Si}$ waveguide. In our devices the active layer for the DFB laser and the EA modulators (or tapers) is identical which eases the fabrication process [12], [13]. The active region consists of 8 InAlGaAs quantum wells with a bandgap wavelength around $1570 \mathrm{~nm}$. The EAM taper is electrically isolated from the laser mesa by etching the InGaAs contact layer $(200 \mathrm{~nm})$ and part of the p-InP cladding layer $(125 \mathrm{~nm}) .8 \mathrm{k} \Omega$ electrical isolation is obtained. The realized devices are shown in Fig. 1(b). Each row consists of one DFB laser (340 $\mu \mathrm{m}$ long) and two EAMs (200 $\mu \mathrm{m}$ long) coupled to a silicon waveguide. The output power of the EML can be collected using a grating coupler on each side.
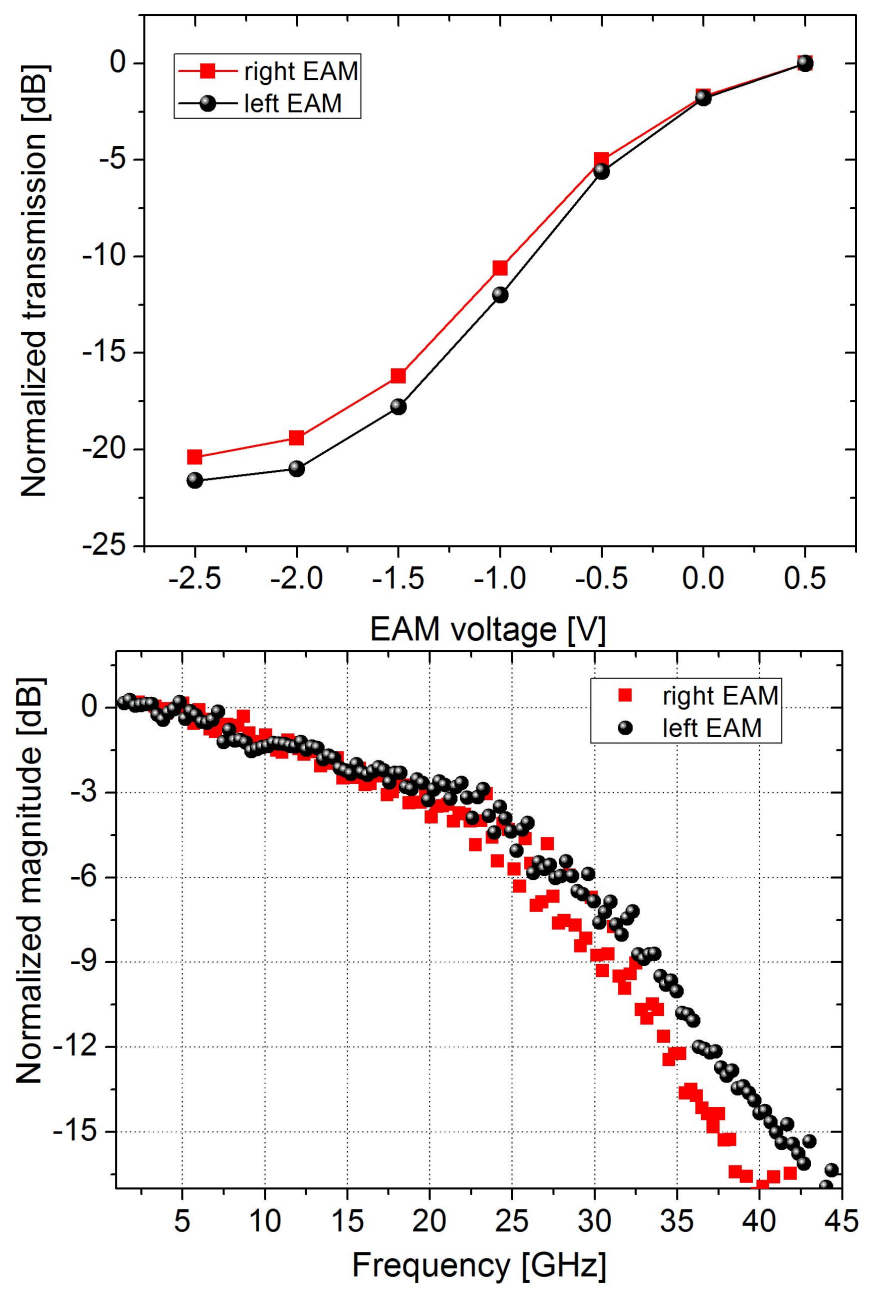

Fig. 2. Normalized output power versus the reverse (DC) bias applied to the EAM (top); small signal modulation characteristics for $-0.8 \mathrm{~V}$ bias on the EAM and $80 \mathrm{~mA}$ bias current to the DFB laser (bottom), $\mathrm{T}=20^{\circ} \mathrm{C}$.

The EML was placed on a temperature-controlled stage during the static and dynamic measurements at the fxed temperature of $20^{\circ} \mathrm{C}$, while the laser was contacted using electrical probe needles. Threshold currents at room temperature of $20 \mathrm{~mA}$, output powers in the silicon waveguide above $3 \mathrm{~mW}$ at $100 \mathrm{~mA}$ bias current, and a series resistance of $7 \Omega$ were measured for the lasers. Single mode emission at $1567 \mathrm{~nm}$ with $40 \mathrm{~dB}$ side mode suppression ratio is obtained. Further optimization of the layer structure is required to enable semicooled operation of the transmitter at $40-50{ }^{\circ} \mathrm{C}$. In order to reduce the insertion loss and increases the extinction ratio of the EAM, lasers operating on the long wavelength side of the gain spectrum are used. These EAMs are fabricated using the same active region as the lasers.

In Fig. 2-(top) the normalized output power of the EML is shown versus the reverse (DC) bias applied to the EAM. For a voltage swing of $1.5 \mathrm{~V}$, an extinction ratio of $15 \mathrm{~dB}$ is obtained. This measurement was done at different DFB laser bias currents and we observed that there is little dependence on the laser bias current, indicating that absorption saturation is not occurring. In order to measure the device modulation bandwidth, the small signal characterization of the two 
a)
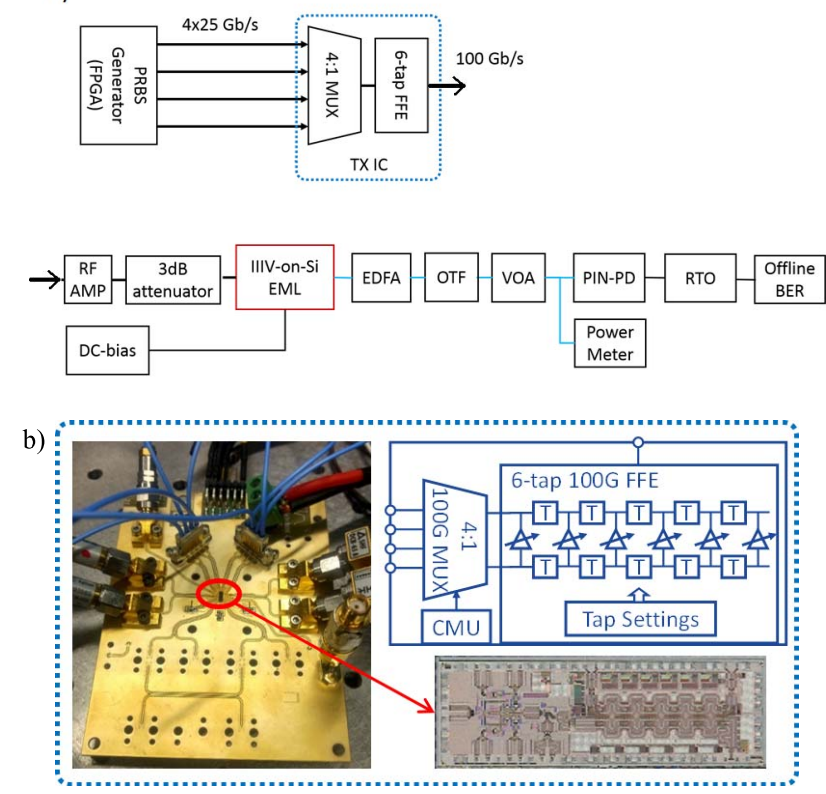

Fig. 3. Schematic of the measurement setup, (a) the image of the electronic $100 \mathrm{~Gb} / \mathrm{s}$ transmitter and (b) its high level block diagram.

EAMs is performed at $80 \mathrm{~mA}$ bias current of the DFB laser (Fig. 2-(bottom). An RC-limited $3 \mathrm{~dB}$ bandwidth of around $20 \mathrm{GHz}$ is obtained with a slow roll-off at higher frequencies.

The left-hand and right-hand side EAM are designed to be identical. From the measurement, this is the case for the small signal response as it is shown in this fgure. The two EAMs integrated with a single laser enables to further improve the compactness of the transmitter in case a parallel single mode $\mathrm{f}$ ber solution is pursued, where both outputs connect to a separate optical fi er. The laser is emitting from both sides with almost the same output power.

\section{LINK DEMONSTRATION}

The large signal performance is performed using the setup shown in Fig. 3. The fi st stage of the transmitter is A XilinX FPGA-board which generates four $25 \mathrm{~Gb} / \mathrm{s}$ binary data streams with $2^{7}-1$ long pseudo-random bit sequences (PRBS). These signals are multiplexed on the TX-IC with the required delays to form a $2^{7}-1$ long PRBS at $100 \mathrm{~Gb} / \mathrm{s}$. Next, a six-tap analog feed forward equalizer (FFE) is used to compensate the frequency roll-off of the components in the link. The TX-IC consumes less than $0.9 \mathrm{~W}$. An RF amplifie with integrated bias-T delivers the signal with a swing of $\sim 2.5 \mathrm{Vpp}$ to the EML via an RF-probe. During bit-error rate (BER) measurements the laser was biased at $80 \mathrm{~mA}$ and the EAM was biased at $-0.8 \mathrm{~V}$.

An erbium-doped f ber amplif er (EDFA) is used to boost the signal power to $\sim 9 \mathrm{dBm}$ before entering a commercial PIN-photodiode $(\mathrm{BW}=45 \mathrm{GHz})$. The ASE of the EDFA is filtere out using an optical tunable flter. The received signal by a $63 \mathrm{GHz} 160 \mathrm{GSa} / \mathrm{s}$ real-time oscilloscope (RTO) is resampled off ine to determine the BER.
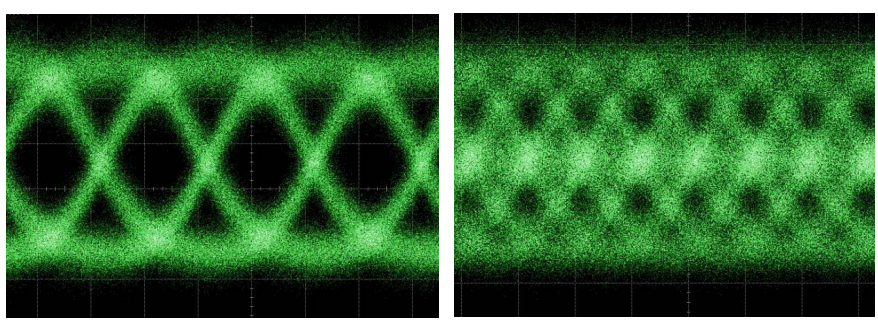

Fig. 4. eye diagrams at $50 \mathrm{~Gb} / \mathrm{s}$ NRZ-OOK (left) and $100 \mathrm{~Gb} / \mathrm{s}$ EDB (right), the DFB laser is biased at $80 \mathrm{~mA}$ and the EAM at $-0.8 \mathrm{~V}, \mathrm{~T}=20^{\circ} \mathrm{C}$.

The optimal sampling point is determined by visual inspection of the eye diagram.

No off-line equalization or other digital signal processing is used. The eye diagrams at $50 \mathrm{~Gb} / \mathrm{s}$ NRZ-OOK and $100 \mathrm{~Gb} / \mathrm{s}$ EDB are shown in Fig. 4. At $100 \mathrm{~Gb} / \mathrm{s}$, a BER of $1.6 \mathrm{e}-3$ was measured for transmission over $\sim 100 \mathrm{~m}$ of single mode $\mathrm{fber}$ (for $9 \mathrm{dBm}$ optical input power to the receiver) which is below the hard decision forward error coding limit with $7 \%$ overhead of $3.8 \mathrm{e}-3$.

\section{CONCLUSION}

In summary, we demonstrated the generation and transmission of a $100 \mathrm{~Gb} / \mathrm{s}$ electrical duobinary signal using a heterogeneously integrated InP-on-Si externally modulated DFB laser without having to rely on any digital signal processing. Since the device consists of two identical EAMs on each side, the device potentially can be used to generate 2 independent $100 \mathrm{~Gb} / \mathrm{s}$ EDB data streams resulting in a single laser $200 \mathrm{~Gb} / \mathrm{s}$ transmitter. Combining two of these devices could be a lowcost and compact option for a parallel single mode $400 \mathrm{GbE}$ transmitter. The fabrication of high performance integrated EA-DFB lasers on Si photonic circuits enables also the integration of $100 \mathrm{Gbps}$ receivers on the same photonic integrated circuit [14].

\section{ACKNOWLEDGEMENTS}

The authors acknowledge 3-5 Lab for supplying the III-V epitaxial wafer.

\section{REFERENCES}

[1] C. Cole, "Beyond 100G client optics," IEEE Commun. Mag., vol. 50, no. 2, pp. 558-566, Feb. 2012. [Online]. Available: http://www.ieee802. org $/ 3 / \mathrm{ba}$

[2] Q. Zhang et al., "Single-lane $180 \mathrm{~Gb} / \mathrm{s}$ SSB-duobinary-PAM-4 signal transmission over $13 \mathrm{~km}$ SSMF," in Proc. Opt. Fiber Commun. Conf. Exhib., Mar. 2017, pp. 1-3.

[3] A. Chiuchiarelli et al., "Single wavelength $100 \mathrm{G}$ real-time transmission for high-speed data center communications," in Proc. OFC, Mar. 2017, pp. 1-3.

[4] J. Lee et al., "Demonstration of 112-Gbit/s optical transmission using 56Gbaud PAM-4 driver and clock-and-data recovery ICS," in Proc. Eur. Conf. Opt. Commun., Sep./Oct. 2015, pp. 1-3.

[5] T. Chan, I.-C. Lu, J. Chen, and W. I. Way, "400-Gb/s transmission over 10-km SSMF using discrete multitone and 1.3- $\mu \mathrm{m}$ EMLs," IEEE Photon. Technol. Lett., vol. 26, no. 16, pp. 1657-1660, Aug. 15, 2014.

[6] P. Dong et al., "Four-channel 100-Gb/s per channel discrete multitone modulation using silicon photonic integrated circuits," J. Lightw. Technol., vol. 34, no. 1, pp. 79-84, Jan. 1, 2016. 
[7] M. Chaciński et al., "Modulation and chirp evaluation of $100 \mathrm{GHz}$ DFB-TWEAM," in Proc. ECOC, Turin, Italy, Sep. 2010, paper Mo.1.F.2.

[8] M. Chacinski, U. Westergren, B. Stoltz, and L. Thylen, "Monolithically integrated DFB-EA for $100 \mathrm{~Gb} / \mathrm{s}$ Ethernet," IEEE Electron Device Lett., vol. 29 , no. 12 , pp. $1312-1314$, Dec. 2008.

[9] M. Verplaetse et al., "Real-time $100 \mathrm{~Gb} / \mathrm{s}$ transmission using threelevel electrical duobinary modulation for short-reach optical interconnects," J. Lightw. Technol., vol. 35, no. 7, pp. 1313-1319, Apr. 1, 2017.

[10] J. Verbist et al., "Real-time $100 \mathrm{~Gb} / \mathrm{s} \mathrm{NRZ} \mathrm{and} \mathrm{EDB} \mathrm{transmission} \mathrm{with} \mathrm{a}$ GeSi electroabsorption modulator for short-reach optical interconnects," J. Lightw. Technol., vol. 36, no. 1, pp. 90-96, Jan. 1, 2018.
[11] H. Zwickel et al., "100 Gbit/s serial transmission using a silicon-organic hybrid $(\mathrm{SOH})$ modulator and a duobinary driver IC," in Proc. OFC, Mar. 2017, pp. 1-3.

[12] A. Ramdane, A. Ougazzaden, F. Devaux, F. Delorme, M. Schneider, and J. Landreau, "Very simple approach for high performance DFB laserelectroabsorption modulator monolithic integration," Electron. Lett., vol. 30, no. 23, pp. 1980-1981, Nov. 1994.

[13] M. Theurer et al., " $2 \times 56 \mathrm{~GB} / \mathrm{s}$ from a double side electroabsorption modulated DFB laser and application in novel optical PAM4 generation," J. Lightw. Technol., vol. 35, no. 4, pp. 706-710, Feb. 15, 2015.

[14] H. Chen et al., "100-Gbps RZ data reception in 67-GHz Si-contacted germanium waveguide p-i-n photodetectors," J. Lightw. Technol., vol. 35, no. 4, pp. 722-726, Feb. 15, 2017. 